\title{
Analysis on the Influence Mechanism of Cooling Water on Turbocharger and Optimum Coolant Mass Flow Rate Intelligent Prediction
}

\author{
Chunping Lu ${ }^{(D)}{ }^{1}$ Jianyu Li ${ }^{(D)},{ }^{1,2}$ and Dongli Tan ${ }^{3}{ }^{3}$ \\ ${ }^{1}$ China Metallurgic Jingcheng (Xiangtan) Heavy Industry Equipment Co., Ltd., Hunan, China \\ ${ }^{2}$ Hunan Valin Xiangtan Iron \& Steel Co., Ltd., Xiangtan 411101, China \\ ${ }^{3}$ Institute of the New Energy and Energy-Saving \& Emission-reduction, Guangxi University of Science and Technology, \\ Liuzhou 545006, China \\ Correspondence should be addressed to Dongli Tan; tandongli2008@163.com
}

Received 1 December 2020; Revised 12 January 2021; Accepted 18 January 2021; Published 27 January 2021

Academic Editor: Jianguo Wang

Copyright (C) 2021 Chunping Lu et al. This is an open access article distributed under the Creative Commons Attribution License, which permits unrestricted use, distribution, and reproduction in any medium, provided the original work is properly cited.

Due to the high speed and high temperature of engine exhaust, the turbocharger bears very high heat load. The heat dissipation of turbocharger is an important factor to determine the service life and performance of turbocharger. In this paper, a mathematical model of the fluid-structure interaction heat transfer of the water-cooled bearing body of turbocharger was established and the cooling performance of a $1.8 \mathrm{~L}$ gasoline engine turbocharger was analyzed. The effects of cooling water inlet flow, engine exhaust temperature, cooling water inlet temperature, and wall roughness of cooling water chamber on the cooling performance of important parts of the bearing body were analyzed by the numerical simulation method. In addition, the cooling water flow required by bearing body with a different structure under different working conditions was studied based on the orthogonal test method. The predicted result shows a good agreement with the experiment result, which could provide a reference for relevant production design and cooling strategy. In the range larger than the thickness of laminar flow bottom layer of the cooling water chamber wall, the increase of wall roughness height can enhance the heat transfer between the fluid and the solid.

\section{Introduction}

As an auxiliary important part of the engine [1], the turbocharger, which usually operates in harsh environment, is an important part in the diesel engine [2] and the turbocharger has been designed as a high-tech product integrating mechanical, electronic, new materials and other disciplines [3]. If the turbocharger is matched with diesel engine, gasoline engine [4], and even hybrid electric vehicle [5], the working performance of engine will be improved and the exhaust emissions will be reduced [6]. The turbocharger technology has been taken in recent decades to satisfy the increasingly strict engine emission regulations [7]. At present, the application of turbocharger is more and more wide, which helps to promote the miniaturization of the engine and makes the engine more efficient and environmentally friendly [8].
When the turbocharger works, it is a rotating machine with high speed and high temperature [9]. As an important component of an engine, the turbocharger has a high requirement for its working performance, reliability, and stability [10]. If the turbocharger operates at high temperature, it may be damaged or stop working completely [11]. The high thermal load makes the heat dissipation become a critical factor that influences the service life of the turbocharger [12]. With the continuous improvement and higher requirements of engines for modern vehicles, the exhaust temperature will become higher and higher [13]. Generally, the turbine shaft rotates at high speed which often reaches $80000-120000 \mathrm{rpm}$ or even higher and generates a great amount of heat. Thus, the turbocharger must meet higher requirements through continuous technical improvement. In order to adapt to 
higher exhaust temperature, two methods can be considered. One way is to develop the high-temperature resistance and oxidation resistance materials [14], and the other way is to cool the turbocharger. Usually, the cooling of turbocharger relies on lubricating oil [15]. The heat generated by bearing rotational friction and the heat flux from the shaft can be adsorbed by the lubricating oil [16]. Pastor et al. [17] had cut off the oil supply and found that the shaft wore out quickly. Chuepenget et al. [18] investigated the thermal effects of lubricating oils with two viscosity grades on turbocharger at low thermal loads and found that the viscosity of lubricating oil had an inversely nonlinear relation with temperature. Podevin et al. [19] investigated how the temperature and pressure of lubricating oil affected the compressor. They found that the most influential factors were compression ratio, compressor power, isentropic efficiency, and mechanical efficiency. Chun et al. [20] had pointed out that the oil inlet temperature, type of oil, and inlet port had a great influence on the cooling performance. Thus, the lubricating oil is important for the turbocharger. However, when matching with the high-strength engine, the effects of lubrication and cooling performance are reduced due to the high temperature of engine lubricating oil, which cannot meet the working reliability requirements of the floating ring when the turbocharger rotor rotates at a high speed of $120000 \mathrm{rpm}$, resulting in bearing wear and turbocharger failure. If the single oil cooling cannot meet the requirements, the water cooling and oil cooling are commonly used [21]. Nowadays, more and more turbochargers are equipped with special oil channels (lubrication) and water channels (cooling), which can decrease the heat load of the turbocharger through the dual heat dissipation of oil and water. Research shows that water can reduce the heat load transferred from the turbine to the compressor by 3-4 times [22]. Moreover, water cooling can reduce the fuel consumption of engine [23]. It is necessary to establish an accurate, general, and quantitative method to analyze the cooling performance of the water-cooled bearing of the turbocharger.

As mentioned above, the turbocharger performance map is obtained under an adiabatic condition [24] and provided by the manufacturer [25]. However, the experiments show that heat transfer cannot be ignored [26]. The heat transfer has a great influence on the efficiency of turbocharger [27], especially for those small turbochargers $[28,29]$. The analysis of the heat transfer process is of guiding significance to further improve the performance of turbocharger and even the engine. There are different models used for the analysis of heat transfer in the turbocharger, which are one-dimensional lumped model [30], lumped capacitance heat transfer model [31,32], 2D model [33], 3D conjugate heat transfer model [34], and neural network model [35]. 1D models focus on axial heat transfer and have the merit of fast analysis. 2D models consider both the radial and axial directions. Serrano et al. [36] had found that the heat losses in small turbocharger at low loads might be higher than those of the mechanical power. In addition, Gao et al. [34] established a 3D conjugated heat transfer model and found that the heat losses could be 2.511 times those of the mechanical power. Serrano et al. [37] put forward different cooling strategies to deal with the burning of trapped oil in the bearing during engine hot-stops; the strategies included improving cooling performance when normally operating and activating electrically driven pumps when the engine stopped. Huang et al. [35] utilized the neural network model to predict the heat transfer in the turbocharger based on turbocharger speed, turbine expansion ratio, and the turbine inlet temperature. They improved the accuracy of the calculation. Schinnerl et al. [38] built a heat transfer model considering friction phenomena to correct the thermomechanical turbine efficiency. Jiaqaing et al. [39] studied the difference between the water-cooled turbochargers with/without considering boiling, and it was found that the simulation results considering boiling were closer to the experimental results. Different parameters were studied by Mohd et al. [40] and they had found that the temperature difference of the turbine's volute was the main reason that affected the efficiency of the turbine.

The design and matching of the cooling system directly affect the economy, reliability, and durability of the turbocharger. The bearing body that supports the sealing ring and floating ring is the main component of the turbocharger. Heat transfer on the turbine side is mostly transferred to the ambient and the rest is transferred to the water or oil in the bearing body [41]. The degree of heat load on the bearing body directly affects the lifespan and working reliability of the sealing ring and bearing. In the cooling system of the turbocharger, the flow of cooling water has a great influence on the cooling performance of the turbocharger. If the cooling water mass flow rate is too low, the insufficient cool will be caused; on the contrary, if the cooling water flow is too large, the excessive cool will be caused, which will cause energy waste. Seeking the best cooling water mass flow rate under various working conditions can not only ensure that the turbocharger works in the best temperature range but also improve the efficiency of the cooling system. Moreover, the good cooling performance can improve the performance, extend the service life, enhance the reliability of the turbocharger, and further reduce the energy consumption and the economic cost. Therefore, it is of great significance to study the relationship between cooling water mass and flow rate at different operating conditions. At the same time, the influence of the structure of the water-cooled bearing on cooling performance is also an important issue to be considered in the design stage.

As it is mentioned, the influence mechanism of cooling water on turbocharger is very important, which is directly related to the performance and emission characteristics of engine. In this paper, the influence mechanism of the cooling water mass flow rate on the cooling performance of the turbocharger is investigated by the improved model. In addition, the optimum cooling water mass flow rate required for the bearing bodies with different structures is studied and predicted under different working conditions. 


\section{Model Description}

\subsection{Mathematic Models}

2.1.1. Fluid Heat Transfer Equation. (1) Mass Conservation Equation. When cooling water and engine oil flow in a steady state, the mass conservation equation can be written as

$$
\frac{\partial \rho}{\partial t}+\operatorname{div}(\rho \mathbf{U})=0
$$

where $\rho$ is the density of the fluid, $\mathrm{kg} / \mathrm{m}^{3}$; $t$ is time, $s$; $\mathrm{U}$ is the velocity vector of the fluid, $\mathrm{m} / \mathrm{s}$.

(2) Momentum Conservation Equation. The change rate of the fluid momentum to time is equal to the sum of various external forces acting on the microelement.

$$
\frac{D(\rho \mathbf{U})}{D t}=\rho \mathbf{F}_{b}+\operatorname{div} \mathbf{P},
$$

where $\mathrm{F}_{b}$ is mass force for the fluid, $\mathrm{N}$; $\mathrm{P}$ is the surface force for the fluid, $10^{-3} \mathrm{~N} / \mathrm{m}$.

The left end of the equation is the inertial force of the fluid in unit volume, and the right end of the equation is the mass force and the surface force for the fluid in unit volume. $\mathrm{P}$ can be obtained as follows:

$$
\mathbf{P}=2 \mu \mathbf{S}+\left\{-p-\frac{2 \mu}{3} \operatorname{div} \mathbf{U}\right\} \mathbf{I},
$$

where $\mu$ is the viscosity coefficient of the fluid, Pa.s; $S$ is the generalized source term; $p$ is the pressure of the fluid; I is unit vector.

Equation (2) can be rewritten as

$$
\frac{\mathrm{D}(\rho \mathbf{U})}{\mathrm{D} t}=\rho \mathbf{F}_{b}-\operatorname{grad} p+\operatorname{div}(2 \mu \mathbf{S})-\frac{2}{3} \operatorname{grad}(\mu \operatorname{div} \mathbf{U}) .
$$

(3) Energy Conservation Equation. The increase of energy in the microelement is equal to the sum of the net heat flow into the microelement and the work done by physical force and surface force on the microelement.

$$
\frac{\partial(\rho T)}{\partial t}+\operatorname{div}(\rho \mathbf{U T})=\operatorname{div}\left[\frac{k}{c_{p}} \operatorname{grad}(T)\right]+S_{T},
$$

where $c_{p}$ is the specific heat capacity, $\mathrm{J} /(\mathrm{kg} \cdot \mathrm{K})$; $T$ is the fluid temperature, $\mathrm{K} ; k$ is the heat transfer coefficient of the fluid, $\mathrm{W} /\left(\mathrm{m}^{2} \cdot \mathrm{K}\right) ; S_{T}$ is the viscous dissipation energy, J. The viscous dissipation energy refers to the internal heat source term of fluid and the part of mechanical energy converted into heat energy due to the viscosity.

2.1.2. Solid Heat Transfer Equation. The heat transfer in the solid is much simpler than that of fluid.

$$
\frac{\partial}{\partial t}\left(\rho_{s} h_{s}\right)+\operatorname{div}\left(\rho_{s} \mathbf{U} h_{s}\right)=\operatorname{div}\left[\lambda_{s} \operatorname{grad}\left(T_{s}\right)\right]+q_{m}
$$

where $\rho_{s}$ is the density, $\mathrm{kg} / \mathrm{m}^{3} ; h_{s}$ is the sensible enthalpy, J; $\lambda_{s}$ is the heat transfer coefficient, $\mathrm{W} /\left(\mathrm{m}^{2} \cdot \mathrm{K}\right) ; T_{s}$ is the temperature, $\mathrm{K} ; q_{m}$ is the volume heat source inside the solid.
2.1.3. K-ع Model. Based on the equation of turbulent kinetic energy $K$, the standard $K-\varepsilon$ model is formed by introducing an equation of turbulent dissipation rate $\varepsilon$.

$$
\begin{aligned}
\frac{\partial}{\partial t}(\rho K)+\frac{\partial}{\partial x_{i}}\left(\rho K u_{i}\right)= & \frac{\partial}{\partial x_{j}}\left[\left(\mu+\frac{\mu_{t}}{\sigma_{K}}\right) \frac{\partial \varepsilon}{\partial x_{j}}\right]+G_{K}+G_{b} \\
& -\rho \varepsilon-Y_{M}+S_{K},
\end{aligned}
$$

where $x_{i}$ means $x, y$, and $z$ direction when $i$ is equal to 1,2 , and 3 separately; $u_{i}$ is the velocity of $\boldsymbol{U}$ in the $x_{i}$ direction, $\mathrm{m} /$ $s ; G_{K}$ and $G_{b}$ are the turbulent kinetic energy produced by different reasons, $\mathrm{m}^{2} / \mathrm{s}^{2} ; Y_{M}$ is the contribution of pulsation expansion in compressible turbulence, $\sigma_{K}$ is turbulent Prandtl number of the $K$ equation, $\sigma_{K}=1.0$, and $S_{K}$ is userdefined source term of the turbulent kinetic energy.

$$
\begin{aligned}
\frac{\partial}{\partial t}(\rho \varepsilon)+\frac{\partial}{\partial x_{i}}\left(\rho \varepsilon u_{i}\right)= & \frac{\partial}{\partial x_{j}}\left[\left(\mu+\frac{\mu_{t}}{\sigma_{\varepsilon}}\right) \frac{\partial \varepsilon}{\partial x_{j}}\right] \\
& +C_{1 \varepsilon} \frac{\varepsilon}{K}\left(G_{k}+C_{3 \varepsilon} G_{b}\right)-C_{2 \varepsilon} \rho \frac{\varepsilon^{2}}{K}+S_{\varepsilon},
\end{aligned}
$$

where $\sigma_{\varepsilon}$ is turbulent Prandtl number of $\varepsilon$ equation, $C_{1 \varepsilon}=1.44, C_{2 \varepsilon}=1.92, C_{3 \varepsilon}=1.44, \sigma_{\varepsilon}=1.22$, and $S_{\varepsilon}$ is userdefined source term of the turbulent dissipation rate.

2.1.4. Fluid-Structure Interaction. In the cooling process, the surface of the water-cooled bearing body of turbocharger transfers heat with compressor, turbine, cooling water, and engine oil in the way of convection and heat conduction. According to the Fourier law of heat conduction and the law of energy conservation, the temperature field of the bearing body meets the following equation:

$$
\lambda\left(\frac{\partial^{2} T_{B}}{\partial x^{2}}+\frac{\partial^{2} T_{B}}{\partial y^{2}}+\frac{\partial^{2} T_{B}}{\partial z^{2}}\right)+q_{v}=\rho c \frac{\partial T_{B}}{\partial t},
$$

where $T_{B}$ is the temperature of bearing body, $\mathrm{K} ; t$ is the time of the heat transfer process; $c$ is the specific heat capacity of material, $\mathrm{J} /(\mathrm{kg} \cdot \mathrm{K}) ; q_{\mathrm{v}}$ is the density of internal heat source of material.

2.2. Model and Grid Independent Test. A simplified turbocharger bearing model was established by Pro/E based on the turbocharger with a $1.8 \mathrm{~L}$ gasoline engine. The cooling channel has two inlets and one outlet. The diameter of the cooling channel is $14 \mathrm{~mm}$. The model of the turbocharger is shown in Figure 1. The grid model (shown in Figure 2) was created by ICEM CFD. Models with different mesh quality are analyzed to perform a grid independent test, which are 428396 elements and 6561866 elements, respectively. The pressure drops between the inlet and outlet are obtained to evaluate whether mesh quality influences the results. At the end of the simulation, the pressure drops are $1979.94 \mathrm{~Pa}$ and 1974.44 $\mathrm{Pa}$, respectively. The difference of pressure drop is $5.5 \mathrm{~Pa}$, which is small enough. This means that the result of 


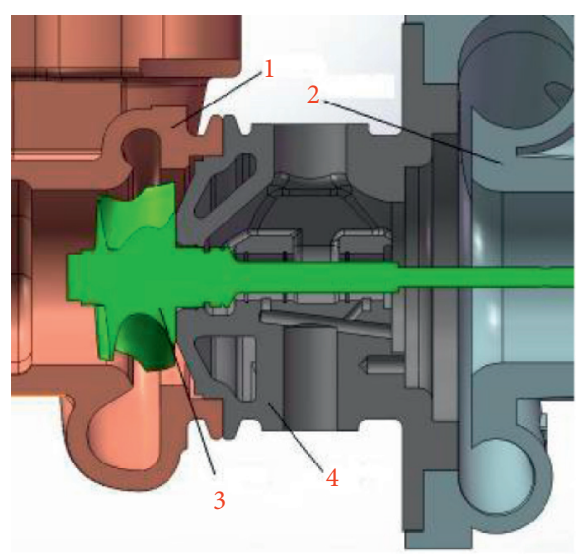
(1) Turbine
(2) Compressor
(3) Axle
(4) Bearing

(a)

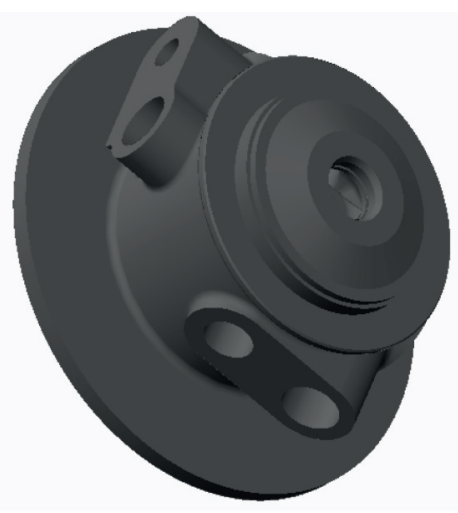

(b)

FIGURE 1: 3D model of the turbocharger. (a) Overview of turbocharger. (b) Bearing housing.

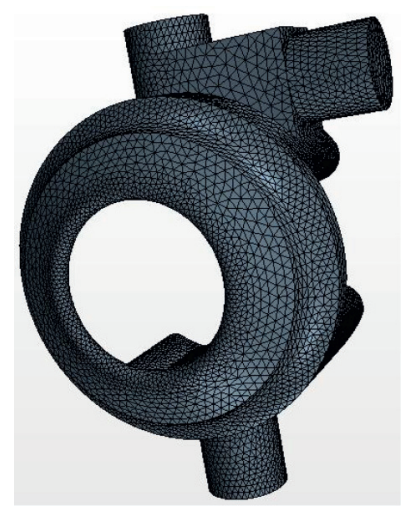

(a)

Figure 2: Grid model of the turbocharger

the first model is acceptable for this simulation. Considering the computing efficiency, higher mesh quality needs more time in calculation, so the 428396 -element model is adopted in this work.

2.3. Optimization of Cooling System. When designing the structure of the water-cooling bearing body of turbocharger, the flow of cooling water at low speed and high speed should be considered. Therefore, the main water inlet and the auxiliary water inlet are designed. When the cooling water flow required for the bearing body cooling is low, the main water inlet is opened and the auxiliary water inlet is closed; when the cooling water flow required for the bearing body cooling is large, the main water inlet and the auxiliary water inlet are also opened at the same time. In this section, the positions of the main water inlet and the auxiliary water inlet are determined by comparing the cooling effects of the two water inlet schemes (Table 1).

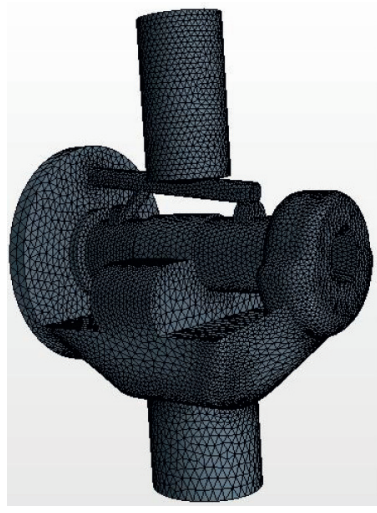

(b)

(a) Water channel. (b) Engine oil channel.

TABLE 1: Layout of water inlet and outlet in two schemes.

\begin{tabular}{lcc}
\hline- & Inlet & Outlet \\
\hline Scheme 1 & Upper inlet & Lower outlet \\
Scheme 2 & Side inlet & Lower outlet \\
\hline
\end{tabular}

Figure 3 shows the velocity vector of the two schemes. It can be found that the maximum velocity of cooling water in scheme 1 is $17.4 \mathrm{~m} / \mathrm{s}$ and the maximum velocity of cooling water is $19.7 \mathrm{~m} / \mathrm{s}$ for scheme 2 . A higher speed of coolant is beneficial for heat convection. Besides, the flow of cooling water in scheme 1 is not as uniform as that in scheme 2 . In scheme 2, the flow of cooling water is relatively stable. The flow velocity of cooling water is fast and uniform, especially in the high-temperature area, but there is a vortex at the outlet. Figure 4 shows the heat transfer coefficient of the two schemes. It can be concluded that the cooling performance of scheme 2 is better than that of scheme 1 . Thus, the side inlet is chosen as the main water inlet and the upper inlet is used as auxiliary water inlet. 


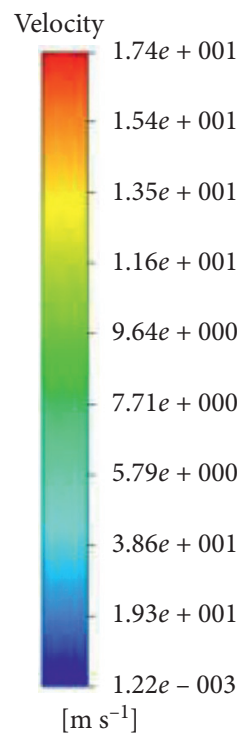

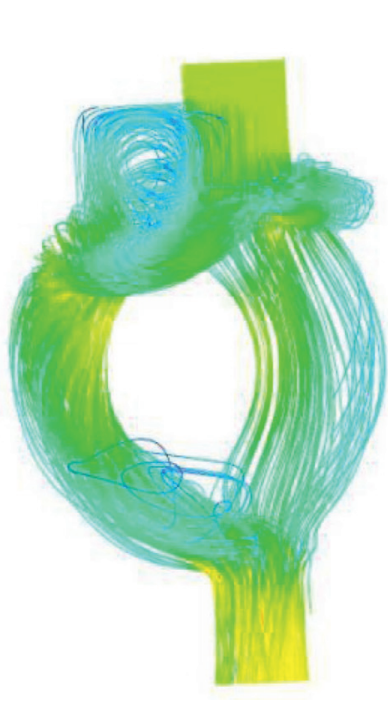

(a)

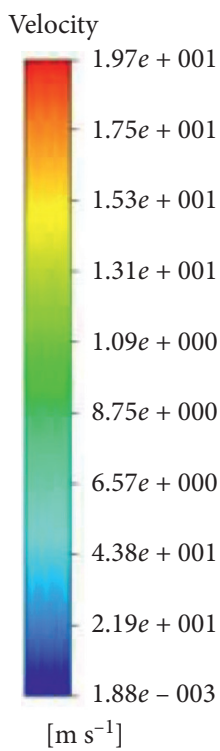

$\left[\mathrm{m} \mathrm{s}^{-1}\right]$

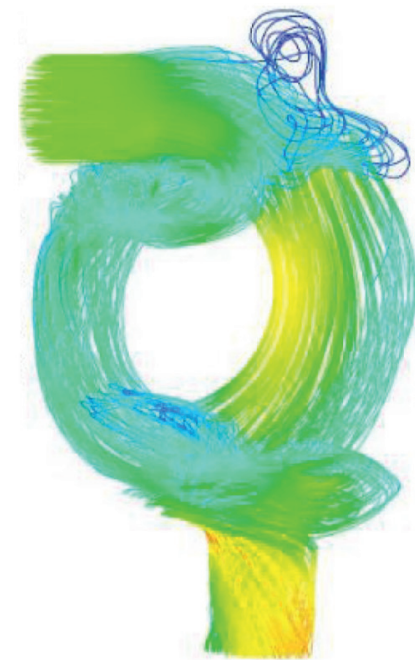

(b)

Figure 3: Velocity vector of the two schemes. (a) Scheme 1. (b) Scheme 2.

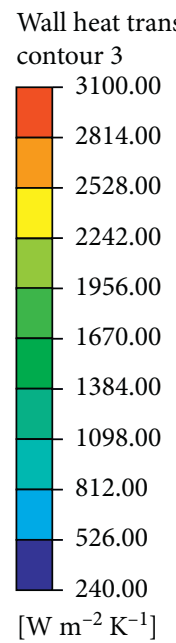

(a)

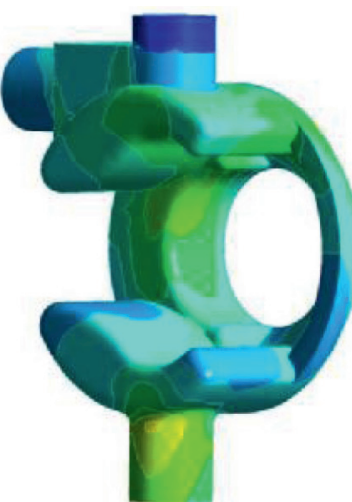

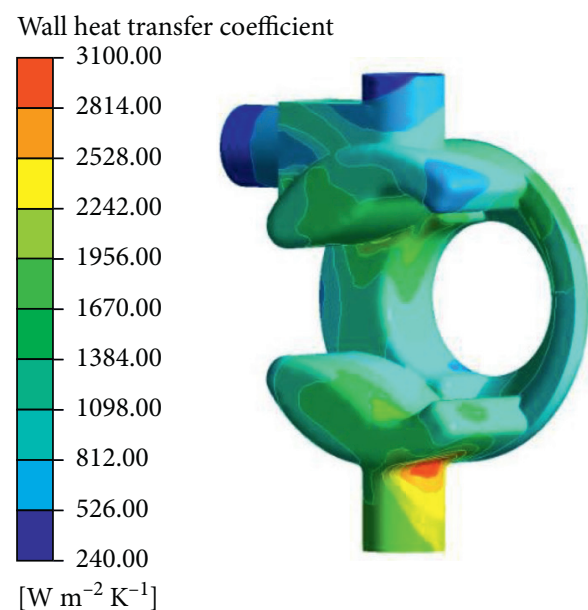

(b)

FIGURE 4: Heat transfer coefficient of the two schemes. (a) Scheme 1. (b) Scheme 2.

2.4. Experimental Validation. The experimental data were obtained from a $1.8 \mathrm{~L}$ engine bench equipped with the turbocharger proposed in this paper. The water inlet and outlet temperature were measured at different exhaust temperature. In addition, the simulation was performed by ANSYS FLUENT. The differences between the experimental data and simulation data are listed in Table 2. It can be seen that the maximum relative error between the experiment and simulation results is $0.8 \%$. Therefore, the simulation results are considered reliable.

\section{Results and Analysis}

3.1. Influence of Exhaust Temperature. The hot end surface of the bearing body is in direct contact with the high-temperature exhaust gas discharged from the engine when the turbocharger is working. Thus, the exhaust temperature plays an important role in the cooling performance. Figure 5 shows the maximum temperature of important parts of bearing body under different exhaust temperature.

It can be concluded that the max. temperature of sealing ring increases with the increase of the exhaust temperature and reduces with the increase of cooling water inlet flow as shown in Figure 5. For instance, when the coolant mass flow rate is $0.5 \mathrm{~kg} / \mathrm{s}$, the maximum temperature of floating ring increased from $192.3^{\circ} \mathrm{C}$ to $223.4^{\circ} \mathrm{C}$ and increased by $16.2 \%$. In addition, the maximum temperature of sealing ring increased from $363.8^{\circ} \mathrm{C}$ to $468.1^{\circ} \mathrm{C}$ and increased by $28.7 \%$ when the coolant mass flow rate is $0.5 \mathrm{~kg} / \mathrm{s}$. It is due to the fact that the increase of exhaust temperature results in the 
TABLE 2: Difference between the experimental data and simulation data.

\begin{tabular}{lcccc}
\hline Exhaust temperature $\left({ }^{\circ} \mathrm{C}\right)$ & Water inlet temperature $\left({ }^{\circ} \mathrm{C}\right)$ & \multicolumn{2}{c}{ Water outlet temperature $\left({ }^{\circ} \mathrm{C}\right)$} & Selative error $(\%)$ \\
& & Experiment & Simulation & 0.80 \\
813.7 & 95.5 & 100.2 & 99.4 & 0.20 \\
763.4 & 95 & 98 & 97.2 & 0.20 \\
752.4 & 95 & 97.7 & 97.8 & 0.41 \\
743.6 & 95 & 97.4 & 97.7 & 0.51 \\
737.3 & 95 & 97.2 & 96.6 & 0.41 \\
732.6 & 94 & 97 & 96.5 & 0.10 \\
725.1 & 94 & 96.6 & 96.4 & 0.21 \\
717.8 & 94 & 96.2 & & \\
\hline
\end{tabular}

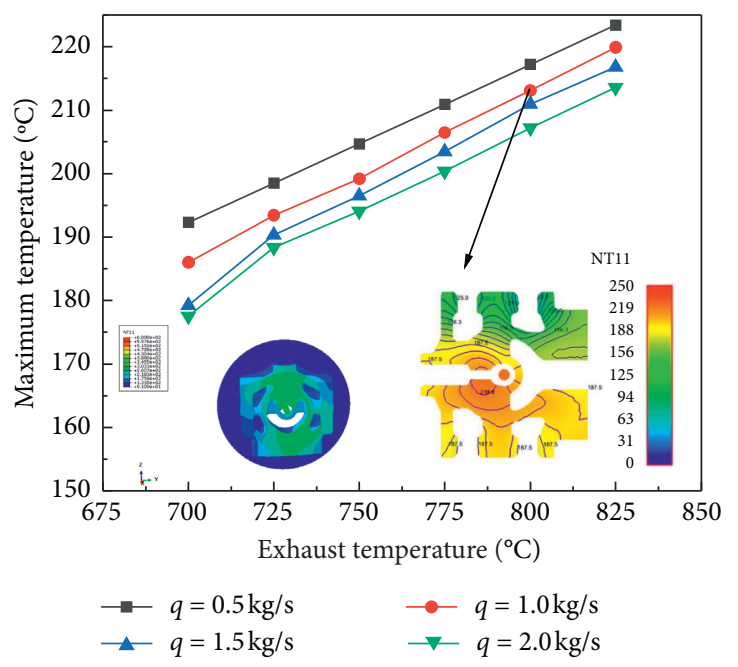

(a)

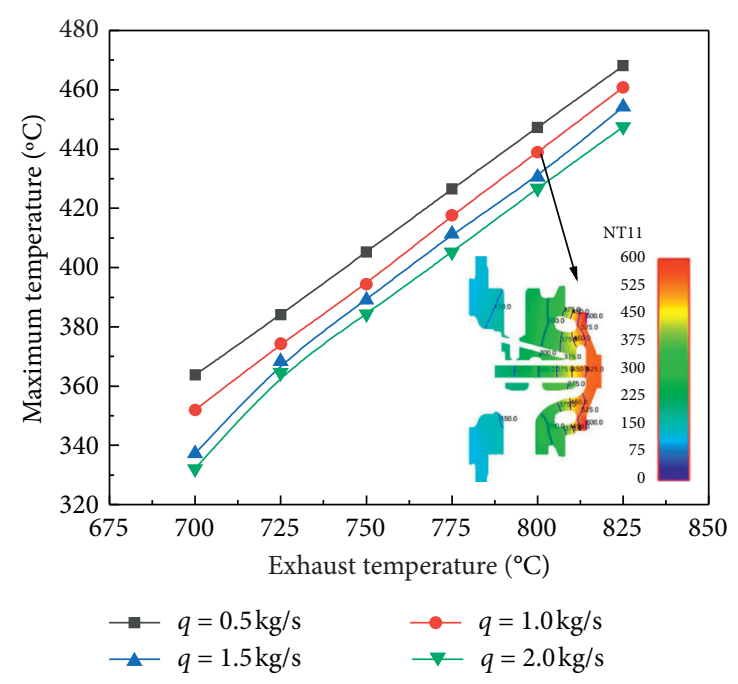

(b)

FIgURe 5: Maximum temperature of important parts of bearing body under different exhaust temperature. (a) Floating ring. (b) Sealing ring.

increase of the heat load at the surface of bearing body and increases the temperature of all parts of bearing body. However, the increase of temperature at the seal ring is larger than that at the floating ring. It is due to the fact that the seal ring locates between the hot end and the cooling chamber, while the floating ring is situated closer to the cooling chamber and away from the hot end. The heat transferred to the floating ring decreases due to the cooling effect of the cooling chamber. Thus, the increase of temperature is smaller.

3.2. Influence of Coolant Mass Flow Rate. The coolant mass flow rate has been a great influence on the heat transfer intensity between water and the coolant chamber wall. Figure 6 shows the maximum temperature at the floating ring under different exhaust temperatures and different coolant mass flow rates. It can be seen that the maximum temperature at the floating ring decreases gradually as the mass flow rate increases. When the mass flow rate increases from $0.25 \mathrm{~kg} / \mathrm{s}$ to $3 \mathrm{~kg} / \mathrm{s}$, the maximum temperature at the floating ring decreases rapidly. The maximum temperature has been reduced by about $29.6 \%$. In addition, when the mass flow rate increases from $3 \mathrm{~kg} / \mathrm{s}$ to $4.5 \mathrm{~kg} / \mathrm{s}$, the maximum temperature at the floating ring decreases slower and finally tends to remain unchanged. The maximum temperature has been reduced by about $5.2 \%$. This indicates that, with the increase of the cooling water mass flow rate, the heat transfer intensity of the coolant changes greatly at first, but when the mass flow rate increases to a certain extent, further increasing the cooling water flow rate has little effect on the reduction in temperature at the floating ring. This is caused by the gradient change of water flow velocity in the normal direction of the cooling water chamber wall, and there is always a layer of laminar bottom with low flow velocity stuck on the chamber wall. Similarly, the heat transfer coefficient of laminar flow is smaller than that of turbulent flow at the same average velocity. When the mass flow rate of cooling water increases, the thickness of the laminar bottom layer on the chamber wall decreases, which results in the enhancement of heat transfer performance and cooling performance between the cooling liquid and the wall, and further reduces the maximum temperature at the floating ring body. When the mass flow rate of cooling water increases to a certain extent, the thickness of the laminar bottom layer on the wall of the water chamber changes little due to the viscosity of the liquid. Thus, the heat transfer performance does not change much. 


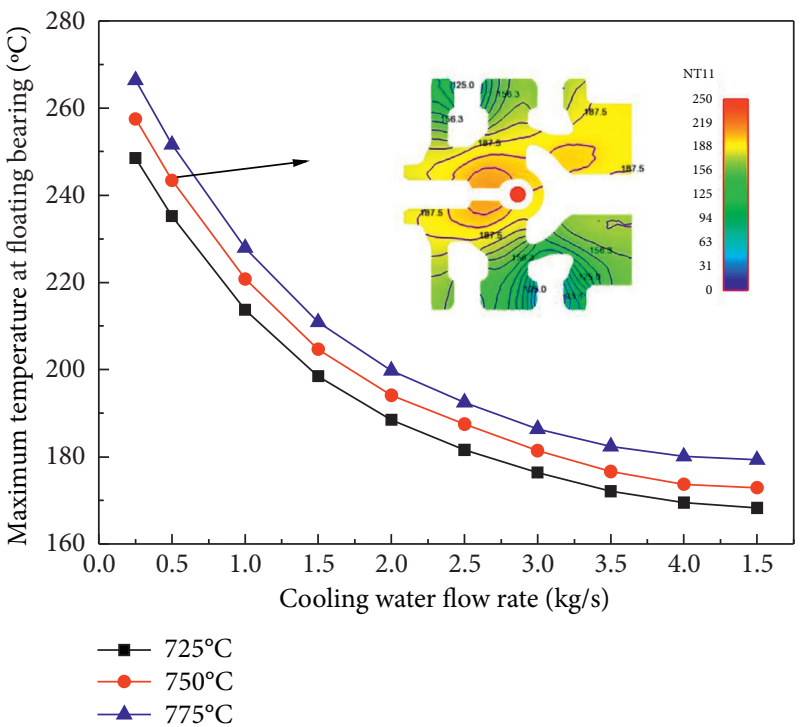

FiguRe 6: Maximum temperature at floating ring under different exhaust temperature and different coolant mass flow rate.

3.3. Influence of Coolant Inlet Temperature. Figure 7 shows the maximum temperature under different water inlet temperature. It can be found that the maximum temperature increases with the increase of exhaust temperature and reduces with the increase of cooling water inlet flow. There is almost a linear relationship between the inlet temperature of cooling water and the maximum temperature of the floating ring and sealing ring. For instance, the maximum temperature of the floating ring increased from $194.4^{\circ} \mathrm{C}$ to $202.1^{\circ} \mathrm{C}$ and marked a $3.96 \%$ increase; the maximum temperature of sealing ring increased from $399.9^{\circ} \mathrm{C}$ to $410.8^{\circ} \mathrm{C}$ and marked a $2.73 \%$ increase. It can be seen that the reduction in the inlet temperature of cooling water has a certain effect on the temperature at the floating ring and sealing ring of bearing body, while the reduction of maximum temperature at the sealing ring is slightly smaller than that at the floating ring. The increase of temperature is larger when the inlet temperature is lower than $70^{\circ} \mathrm{C}$, while it is smaller when the inlet temperature is above $70^{\circ} \mathrm{C}$. The reason is that the heat from engine exhaust is constant; when the cooling water (below $70^{\circ} \mathrm{C}$ ) passes through the water chamber, the heat transfer between the water flow and the bearing wall is relatively large due to the large temperature difference. Therefore, when the coolant inlet temperature is low, the maximum temperatures of the floating ring and the sealing ring increase rapidly with the increase of the water inlet temperature. As the cooling water temperature further increases above $70^{\circ} \mathrm{C}$, the temperature difference between the water flow and the bearing wall decreases, and the heat transfer between the water flow and the bearing wall temperature will also decrease. Thus, the temperature rise rate of the important parts of the bearing body will slow down. The reduction in the temperature of the cooling water has a certain effect on the cooling performance. However, the method of reducing the cooling water inlet temperature to enhance the cooling performance of the bearing body should be avoided as much as possible in order to ensure the normal operation and prolong the service life of the turbocharger.
3.4. Influence of Wall Roughness of Water Chamber. The roughness of the cooling water chamber wall of the bearing body affects the flow resistance and heat transfer performance of the coolant. Table 3 shows the influence of wall roughness on the temperature of important position under different wall roughness.

In Table 3, it can be seen that the maximum temperature at the floating ring and the sealing ring of the bearing body increases firstly and then decreases with the increase of the roughness of the water chamber wall; the maximum temperature at chamber wall changes by a small margin, which can be regarded as unchanged. It is due to the fact that the surface roughness has a great influence on the flow state of the fluid near the water chamber wall, thus affecting its flow and heat transfer. At the place near the water chamber wall, the flow state of the coolant is laminar flow, and the Reynolds number in the laminar bottom layer is relatively low. When the roughness height of the water chamber wall does not exceed the thickness of the laminar bottom layer, increasing the roughness height will form a stagnant vortex area, in which the thermal resistance of the fluid is large. Therefore, increasing the wall roughness in the bottom layer of laminar flow could weaken the heat transfer, resulting in increase of the maximum temperatures of the water chamber wall and the floating ring and the sealing ring. When the roughness height of the water chamber wall increases more than the thickness of the bottom layer of laminar flow, the flow state of the fluid becomes turbulent flow or transition flow. When the roughness height of the chamber wall continues to increase, the vortex formed near the roughness will increase the disturbance of the fluid and enhance the heat transfer performance with the acceleration of fluid flow speed. Thus, the maximum temperature of the cooling water chamber wall and the maximum temperature of the floating ring and the sealing ring on the bearing body are reduced.

Generally speaking, in the range larger than the bottom layer thickness of the laminar flow on the chamber wall, the increase of the wall roughness height can enhance the heat 


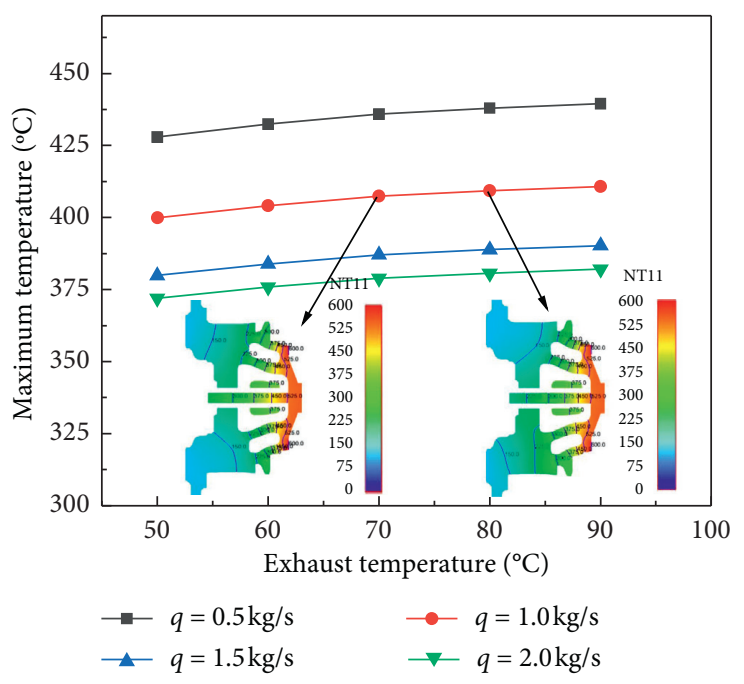

(a)

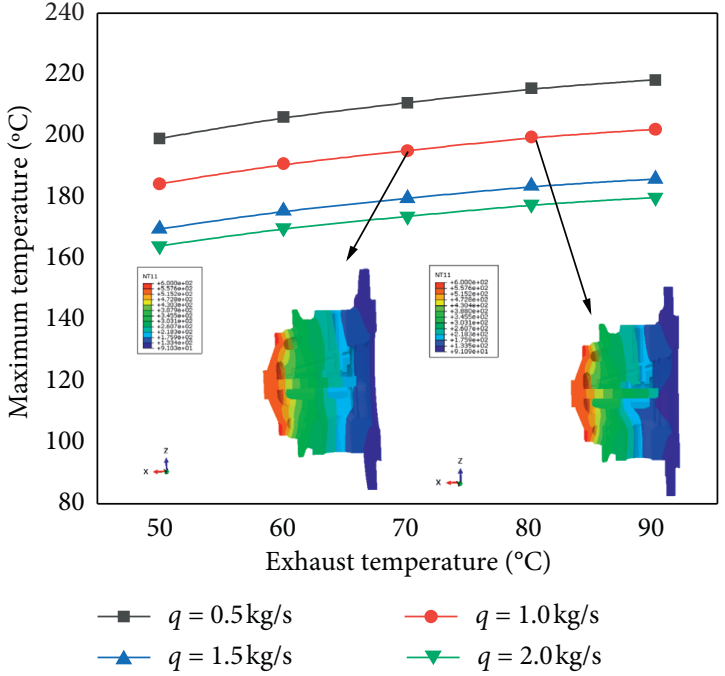

(b)

FIgURE 7: Maximum temperature under different water inlet temperature at (a) floating ring and (b) sealing ring.

TABLE 3: Influence of wall roughness on the temperature of important position.

\begin{tabular}{lcccc}
\hline Wall roughness $(\mathrm{mm})$ & 0 & 1 & 2 & 3 \\
\hline Maximum temperature at floating ring $\left({ }^{\circ} \mathrm{C}\right)$ & 198.9 & 203.4 & 204.7 & 201.5 \\
Maximum temperature at sealing ring $\left({ }^{\circ} \mathrm{C}\right)$ & 398.5 & 401.3 & 405.3 & 402.1 \\
Maximum temperature at wall chamber $\left({ }^{\circ} \mathrm{C}\right)$ & 97.3 & 97.6 & 97.7 & 409.8 \\
\hline
\end{tabular}

transfer between the fluid and the solid and reduce the overall heat load of the bearing body. But the increase of the wall roughness will not have a great impact on the flow resistance of the cooling water in the bearing body due to the high velocity of the coolant. Similarly, the wall roughness height of the bearing body is limited by the structure of the cooling water chamber and the economic cost of manufacturing. Therefore, many factors should be considered in the design of wall roughness.

\section{Intelligent Prediction of Optimum Coolant Mass Flow Rate}

4.1. Orthogonal Test. The orthogonal experiment design is a design method to study multiple factors and multiple levels. According to the orthogonality, some representative points are selected from the overall test for the experiment. These representative points have the uniform dispersion, integrity, and comparability characteristics. Orthogonal experimental design is the main method of fractional factorial design. It is a high-efficiency, fast, and economical experimental design method. Thus, the orthogonal experiment design is to replace the comprehensive experiment with the partial experiment, to investigate the influence of the factors themselves and their interaction with other factors on the objective function from the perspective of integrity, and to understand the comprehensive experiment situation through the analysis of the partial experiment results.
In the paper, the effect of exhaust temperature on the performance of turbocharger is investigated by the orthogonal experiment design. From the analysis in Section 3, it can be found that the engine exhaust temperature and cooling water mass flow rate have a great influence on the cooling of the bearing body. Besides, the impact of the structure of the bearing body on the cooling performance cannot be ignored, such as the cross-sectional area of the cooling water inlet and outlet and the hot end area of the bearing body. In this section, the optimum coolant mass flow rate is calculated under different conditions based on the orthogonal test.

\subsubsection{Determination of Various Factors and Levels. (a) \\ Hot end area of bearing body}

Because the hot end of the water-cooled bearing body has a direct contact with the high-temperature exhaust gas from the engine, the hot end of the water-cooled bearing body bears high thermal load from the exhaust gas, and it is the part with the highest temperature of the bearing body. The outer surface of the hot end is directly exposed to the hightemperature gas in the volute, and the inner surface of the hot end has a contact with the turbine. The study of the relationship between the hot end area and the cooling performance of the bearing body is helpful to further optimize the structure of the bearing body. In this paper, five levels of hot end area 
TABLE 4: Factors and levels.

\begin{tabular}{lccc}
\hline Factors and levels & A (hot end area $/ \mathrm{mm}^{2}$ ) & B (inlet and outlet area $/ \mathrm{mm}^{2}$ ) & C (engine exhaust temperature $/{ }^{\circ} \mathrm{C}$ ) \\
\hline 1 & 1080 & 78.5 & 700 \\
2 & 1300 & 113.1 & 725 \\
3 & 1560 & 154 & 750 \\
4 & 1850 & 201 & 775 \\
5 & 2170 & 254 & 800 \\
\hline
\end{tabular}

TABLe 5: Experimental schemes and results.

\begin{tabular}{|c|c|c|c|c|}
\hline Factors experiment & $\mathrm{A}\left(\mathrm{mm}^{2}\right)$ & $\mathrm{B}\left(\mathrm{mm}^{2}\right)$ & $\mathrm{C}\left({ }^{\circ} \mathrm{C}\right)$ & Coolant mass flow rate $(\mathrm{kg} / \mathrm{s})$ \\
\hline 1 & 1080 & 78.5 & 700 & 0.32 \\
\hline 2 & 1080 & 113.1 & 725 & 0.55 \\
\hline 3 & 1080 & 154 & 750 & 0.77 \\
\hline 4 & 1080 & 201 & 775 & 1.09 \\
\hline 5 & 1080 & 254 & 800 & 1.46 \\
\hline 6 & 1300 & 78.5 & 725 & 0.6 \\
\hline 7 & 1300 & 113.1 & 750 & 0.76 \\
\hline 8 & 1300 & 154 & 775 & 0.98 \\
\hline 9 & 1300 & 201 & 800 & 1.33 \\
\hline 10 & 1300 & 254 & 700 & 0.74 \\
\hline 11 & 1560 & 78.5 & 750 & 0.75 \\
\hline 12 & 1560 & 113.1 & 775 & 1.05 \\
\hline 13 & 1560 & 154 & 800 & 1.24 \\
\hline 14 & 1560 & 201 & 700 & 0.66 \\
\hline 15 & 1560 & 254 & 725 & 0.95 \\
\hline 16 & 1850 & 78.5 & 775 & 0.95 \\
\hline 17 & 1850 & 113.1 & 800 & 1.26 \\
\hline 18 & 1850 & 154 & 700 & 0.58 \\
\hline 19 & 1850 & 201 & 725 & 0.88 \\
\hline 20 & 1850 & 254 & 750 & 0.96 \\
\hline 21 & 2170 & 78.5 & 800 & 1.14 \\
\hline 22 & 2170 & 113.1 & 700 & 0.55 \\
\hline 23 & 2170 & 154 & 725 & 0.79 \\
\hline 24 & 2170 & 201 & 750 & 1.09 \\
\hline 25 & 2170 & 254 & 775 & 1.42 \\
\hline
\end{tabular}

are selected, which are $1080,1300,1560,1850$, and 2170 (unit: $\mathrm{mm}^{2}$ ).

(b) Sectional area of water inlet and outlet of bearing body

The change in the cross-sectional area affects the flow velocity of cooling water in bearing body and has a great influence on the flow and heat transfer of cooling water. The research on the relationship between the cooling performance and the crosssectional area of the water inlet and outlet of the bearing body is beneficial for further optimizing the structure of the bearing body. In this paper, the cross-sectional area of the inlet and outlet is selected as 5 levels, which are 78.5, 113.1, 154, 201, and 254 (unit: $\mathrm{mm}^{2}$ ).

(c) Engine exhaust temperature

The change in exhaust temperature directly affects the thermal load of the bearing body. In this paper, five levels of engine exhaust temperature are selected, which are $700,725,750,775$, and 800 (unit: ${ }^{\circ} \mathrm{C}$ ), respectively. Table 4 shows the factors and levels of the orthogonal test.

4.1.2. Experimental Scheme and Results. The orthogonal test was designed based on the factors and levels determined in Table 4; the optimum coolant mass flow rates under different conditions are calculated and listed in Table 5. Those results could be used as the reference for the smart prediction of optimum coolant mass flow rate.

4.2. Support Vector Machine. Support vector machine (SVM) is developed to solve pattern recognition problems [42] and then extended for function estimation problems [42]. At present, it has been widely studied and applied in many research fields and has a good application prospect in various prediction fields. In this paper, the prediction of optimum coolant mass flow rate was investigated by the SVM method.

Figure 8 shows the flow chart of SVM prediction model based on least squares. First, the main factors that affect the 


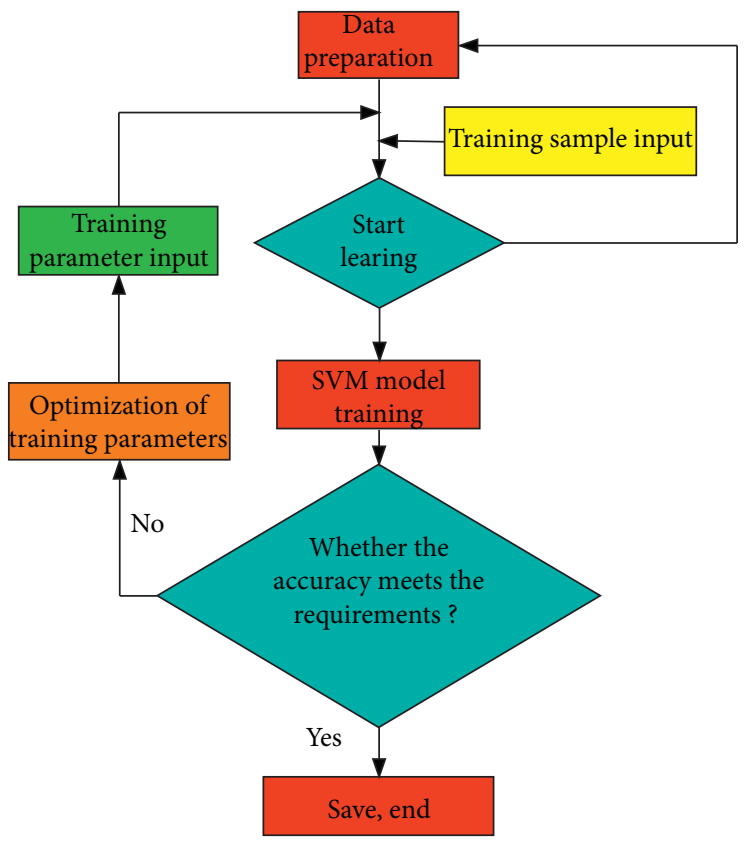

FIGURE 8: Flow chart of SVM prediction model.

Table 6: Prediction of optimum coolant mass flow rate based on SVM.

\begin{tabular}{|c|c|c|c|c|c|c|}
\hline $\begin{array}{l}\text { Experiment } \\
\text { number }\end{array}$ & $\begin{array}{l}\text { Hot end area } \\
\left(\mathrm{mm}^{2}\right)\end{array}$ & $\begin{array}{l}\text { Inlet and outlet } \\
\text { area }\left(\mathrm{mm}^{2}\right)\end{array}$ & $\begin{array}{c}\text { Exhaust } \\
\text { temperature }\left({ }^{\circ} \mathrm{C}\right)\end{array}$ & $\begin{array}{c}\text { Experiment results } \\
\left(\mathrm{kg} \cdot \mathrm{s}^{-1}\right)\end{array}$ & $\begin{array}{c}\text { Prediction results } \\
\left(\mathrm{kg} \cdot \mathrm{s}^{-1}\right)\end{array}$ & $\begin{array}{c}\text { Relative error } \eta \\
(\%)\end{array}$ \\
\hline 1 & 1080 & 154 & 700 & 0.42 & 0.4602 & 9.57 \\
\hline 2 & 2170 & 78.5 & 700 & 0.45 & 0.4523 & 0.51 \\
\hline 3 & 1080 & 78.5 & 725 & 0.47 & 0.514 & 9.36 \\
\hline 4 & 1300 & 154 & 700 & 0.48 & 0.5101 & 6.27 \\
\hline 5 & 1560 & 154 & 700 & 0.55 & 0.5594 & 1.71 \\
\hline 6 & 2170 & 154 & 700 & 0.61 & 0.6568 & 7.67 \\
\hline 7 & 1080 & 113.1 & 750 & 0.73 & 0.7336 & 0.49 \\
\hline 8 & 1560 & 154 & 725 & 0.73 & 0.6988 & 4.27 \\
\hline 9 & 1560 & 201 & 725 & 0.85 & 0.7808 & 8.14 \\
\hline 10 & 1850 & 154 & 750 & 0.92 & 0.9058 & 1.54 \\
\hline 11 & 1300 & 154 & 775 & 0.94 & 1.0174 & 8.23 \\
\hline 12 & 1850 & 201 & 750 & 1.06 & 0.9896 & 6.64 \\
\hline 13 & 1850 & 254 & 775 & 1.13 & 1.2764 & 12.9 \\
\hline 14 & 1300 & 154 & 800 & 1.15 & 1.2448 & 8.24 \\
\hline 15 & 1560 & 78.5 & 825 & 1.24 & 1.3925 & 12.3 \\
\hline 16 & 2170 & 254 & 800 & 1.56 & 1.6317 & 4.59 \\
\hline
\end{tabular}

cooling water flow are screened out, and a support vector machine regression problem with three inputs (influencing factors) and one output (cooling water flow) was constructed. Then, the training samples are pretreated by MATLAB to eliminate the influence of the dimension and unit of each factor and improve the training speed. After the optimization of training parameters, the kernel function of the SVM model and its corresponding parameters (the regularization parameter $\gamma$ and the kernel function parameter $\sigma_{2}$ ) are determined. After a large number of experiments with different parameter combinations, the ideal values of two parameters were obtained, which were $\gamma=6025.92$ and $\sigma_{2}=319.55$.

Table 6 lists the prediction results of the optimum mass flow rate. Figure 9 shows the difference between the experimental results and the simulation results.

In Table 6, it can be seen that the prediction results of optimum coolant mass flow rate based on SVM for the bearing body with different structures under different working conditions are good, the minimum relative error is $0.49 \%$, the maximum relative error is $12.9 \%$, and the average value of relative error is $5.39 \%$. It can be seen from Figure 9 


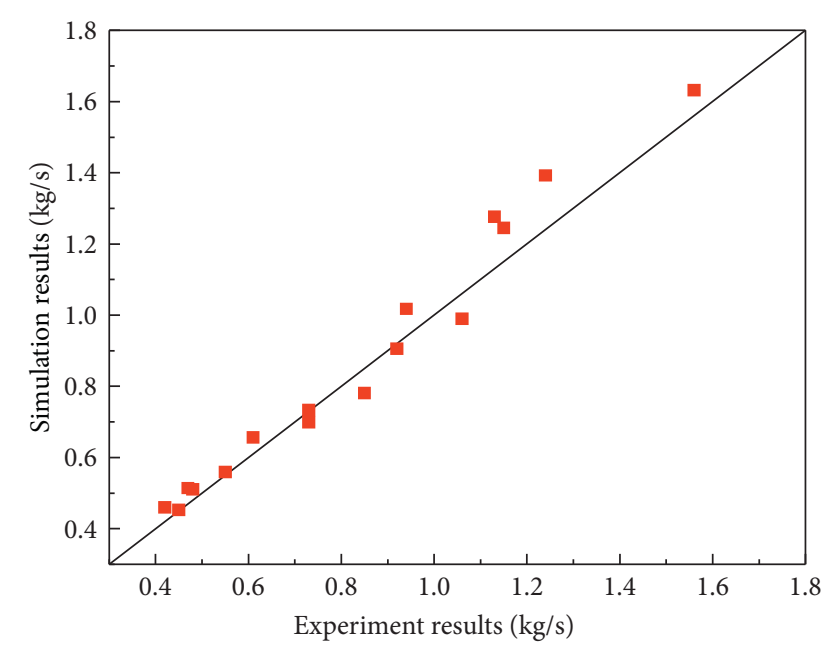

Figure 9: Difference between the experimental results and the simulation results.

that the SVM prediction model has good performance, and the simulation results predicted by the SVM prediction model are relatively close to the experimental value.

\section{Conclusion}

With the development in the energy crisis [4,43-49] and environmental problems [49-57], the effective control of energy saving and the reduction emissions from engines are a primary area of focus for scholars. In the work, a mathematical model of fluid-structure interaction heat transfer of bearing body was developed and employed to investigate the cooling mechanism of the water-cooled bearing body of turbocharger. The results show that the cooling water can effectively reduce the heat transfer from the turbine to the compressor. The main works of this paper are concluded:

(1) Two kinds of water inlet schemes are compared based on the flow and heat transfer performance. Then the side water inlet should be selected as the main water inlet and the upper water inlet is used as the auxiliary water inlet.

(2) The cooling water inlet flow, engine exhaust temperature, cooling water inlet temperature, and wall roughness of the cooling water chamber have a great influence on the cooling performance of important parts of the bearing body. More specifically, the increase of engine exhaust temperature will result in the increase of contact heat load at the hot end of the water-cooled bearing body, which is an important factor affecting the temperature of the important parts of the water-cooled bearing body. In addition, the increase of cooling water flow rate will result in the increase of velocity, and the thickness of the laminar bottom layer on the wall surface of the cooling water chamber decreases, which strengthens the heat exchange between the coolant and the wall surface. When the mass flow rate reaches a certain degree, further increasing the mass flow rate has a little effect on the cooling performance due to the effect of liquid viscosity. Reducing the coolant inlet temperature has a certain effect on reducing the overall heat load of the bearing body. The heat transfer between fluid and solid can be enhanced by the increase of the wall roughness in the range larger than the bottom layer thickness.

(3) The SVM prediction model has a good performance, and the simulation results predicted by the SVM prediction model are relatively close to the experimental value. The average value of relative error is $5.39 \%$.

The results of the study have recommended the SVM prediction model that can improve the calculation accuracy. In future studies, the effects of different parameters on the service life and performance of turbocharger will be examined.

\section{Nomenclature}

$C_{1 \varepsilon}, C_{2 \varepsilon}, \quad \varepsilon$ equation constants

$C_{3 \varepsilon}$ :

$c:$

$c_{p}:$

$F_{b}$ :

$G_{k}$ :

$G_{b}$ :

$h_{s}$ :

I:

k:

K:

$p:$

$P$ :

$q_{m}$ :

$q_{v}:$

$S:$

$S_{T}$ :

$S_{k}$ :

$S_{\varepsilon}$ :

$T:$

$T_{s}$ :

$T_{B}$ :

$t:$

U:

$u_{i}$ :

$x_{i}$ :

$Y_{M}$ :

$\varepsilon:$

$\sigma_{k}:$

$\sigma_{\varepsilon}:$

$\sigma_{2}$

$\lambda_{\mathrm{s}}$ :

$\rho:$

$\rho_{s}:$

$\mu:$

$\gamma:$
Specific heat capacity of material, $\mathrm{J} /(\mathrm{kg} \cdot \mathrm{K})$

Specific heat capacity of fluid, $\mathrm{J} /(\mathrm{kg} \cdot \mathrm{K})$

Mass force for the fluid, $\mathrm{N}$

Turbulent kinetic energy produced by laminar gradient, $\mathrm{m}^{2} / \mathrm{s}^{2}$

Turbulent kinetic energy produced by buoyancy, $\mathrm{m}^{2} / \mathrm{s}^{2}$

\section{Sensible enthalpy, J}

Unit vector

Heat transfer coefficient, $\mathrm{W} /\left(\mathrm{m}^{2} \cdot \mathrm{K}\right)$

Turbulent kinetic energy, $\mathrm{m}^{2} / \mathrm{s}^{2}$

Pressure of the fluid, $\mathrm{Pa}$

Surface force for the fluid, $10^{-3} \mathrm{~N} / \mathrm{m}$

Volume heat source inside the solid

Density of internal heat source of material

Generalized source term

Viscous dissipation energy, J

User-defined source term of $k$ equation

User-defined source term of dissipation rate

Fluid temperature, $\mathrm{K}$

Solid temperature, $\mathrm{K}$

Temperature of bearing body, $\mathrm{K}$

Time, $s$

Fluid velocity vector of the fluid, $\mathrm{m} / \mathrm{s}$

Velocity of $\boldsymbol{U}$ in the $x_{i}$ direction, $\mathrm{m} / \mathrm{s}$

$x, y$, and $z$ direction when $i=1,2$, and 3

separately

Contribution of pulsation expansion.

Turbulent dissipation rate, \%

Prandtl number of turbulent kinetic energy

Prandtl number of turbulent dissipation rate

Kernel function parameter

Heat transfer coefficient of solid, $\mathrm{W} /\left(\mathrm{m}^{2} \cdot \mathrm{K}\right)$

Fluid density, $\mathrm{kg} / \mathrm{m}^{3}$

Solid density, $\mathrm{kg} / \mathrm{m}^{3}$

Viscosity coefficient, Pa.s

Regularization parameter. 


\section{Data Availability}

All data used to support the findings of this study are included within the article.

\section{Conflicts of Interest}

The authors declare that there are no conflicts of interest regarding the publication of this article.

\section{Acknowledgments}

This work was supported by the Natural Science Foundation of Guangxi under the research grant nos. 2018GXNSFAA281267 and 2018GXNSFAA294072, the Guangxi Young and Middle-Aged College Teachers Basic Research Ability Promotion Project under the research grant no. 2020KY39008, and the Key Scientific Research Projects of Guangxi Vocational and Technical Institute of Industry under the research grant no. $2019015 \mathrm{KY} 025$.

\section{References}

[1] D. Zhao and L. Li, "Effect of choked outlet on transient energy growth analysis of a thermoacoustic system," Applied Energy, vol. 160, pp. 502-510, 2015.

[2] S. Li, P. Wu, L. Cao, D. Wu, and Y. She, "CFD simulation of dynamic characteristics of a solenoid valve for exhaust gas turbocharger system," Applied Thermal Engineering, vol. 110, pp. 213-222, 2017.

[3] D. Zhao, C. Ji, X. Li, and S. Li, "Mitigation of premixed flamesustained thermoacoustic oscillations using an electrical heater," International Journal of Heat and Mass Transfer, vol. 86, pp. 309-318, 2015.

[4] G. Wu, D. Wu, Y. L. Li, and L. Meng, "Effect of acetone-nbutanol-ethanol (ABE) as an oxygenate on combustion, performance, and emission characteristics of a spark ignition engine," Journal of Chemistry, vol. 2020, Article ID 7468651, 11 pages, 2020.

[5] M. H. Padzillah, S. Rajoo, and R. F. Martinez-Botas, "Influence of speed and frequency towards the automotive turbocharger turbine performance under pulsating flow conditionsfluence of speed and frequency towards the automotive turbocharger turbine performance under pulsating flow conditions," Energy Conversion and Management, vol. 80 , pp. 416-428, 2014.

[6] E. Jiaqiang, G. Liu, Z Zhang et al., "Effect analysis on cold starting performance enhancement of a diesel engine fueled with biodiesel fuel based on an improved thermodynamic model," Applied Energy, vol. 243, pp. 321-335, 2019.

[7] E. Jiaqiang, W. Zuo, J. Gao, Q. Peng, Z. Zhang, and P. Hieu, "Effect analysis on pressure drop of the continuous regeneration-diesel particulate filter based on $\mathrm{NO}_{2}$ assisted regeneration," Applied Thermal Engineering, vol. 100, pp. 356-366, 2016.

[8] E. Jiaqiang, Z. Zhang, J Chen et al., "Performance and emission evaluation of a marine diesel engine fueled by water biodiesel-diesel emulsion blends with a fuel additive of a cerium oxide nanoparticle," Energy Conversion and Management, vol. 169, pp. 194-205, 2018.

[9] G. Wu, D. Wu, Y. Li, and L. Meng, "Effect of acetone-nbutanol-ethanol (ABE) as an oxygenate on combustion, performance, and emission characteristics of a spark ignition engine," Journal of Chemistry, vol. 2020, Article ID 7468651, 11 pages, 2020.

[10] Z. Zhang, E. Jiaqiang, J. Chen et al., "Effects of boiling heat transfer on the performance enhancement of a medium speed diesel engine fueled with diesel and rapeseed methyl ester," Applied Thermal Engineering, vol. 169, Article ID 114984, 2020.

[11] E. Jiaqiang, M. Liu, Y. W. Deng, H. Zhu, and J. K. Gong, "Influence analysis of monolith structure on regeneration temperature in the process of microwave regeneration in diesel particulate filter," Canadian Journal of Chemical Engineering, vol. 94, pp. 168-174, 2016.

[12] E. Jiaqiang, L. F. Xie, Q. S. Zuo, and G. J. Zhang, "Effect analysis on regeneration speed of continuous regenerationdiesel particulate filter based on $\mathrm{NO}_{2}$-assisted regeneration," Atmospheric Pollution Research, vol. 7, pp. 9-17, 2016.

[13] X. H. Zhao, E. Jiaqiang, G. L. Liao, F. Zhang, J. W. Chen, and Y. W. Deng, "Numerical simulation study on soot continuous regeneration combustion model of diesel particulate filter under exhaust gas heavy load," Fuel, vol. 287, Article ID 119795, 2021.

[14] Q. Zuo, Y. Xie, E. Jiaqiang et al., "Effect of different exhaust parameters on NO conversion efficiency enhancement of a dual-carrier catalytic converter in the gasoline engine," Energy, vol. 191, Article ID 116521, 2020.

[15] Z. Zhang, J. Ye, D Tan et al., "The effects of Fe2O3 based DOC and SCR catalyst on the combustion and emission characteristics of a diesel engine fueled with biodiesel," Fuel, vol. 290, Article ID 120039, 2021.

[16] D. C. Quiros, S. Yoon, H. A. Dwyer, J. F. Collins, Y. Zhu, and T. Huai, "Measuring particulate matter emissions during parked active diesel particulate filter regeneration of heavyduty diesel trucks," Journal of Aerosol Science, vol. 73, pp. 48-62, 2014.

[17] J. V. Pastor, J. R. Serrano, V. Dolz, M. A. López, and F. Bouffaud, "Study of turbocharger shaft motion by means of non-invasive optical techniques: application to the behaviour analysis in turbocharger lubrication failures," Mechanical Systems and Signal Processing, vol. 32, pp. 292-305, 2012.

[18] S. Chuepeng and S. Saipom, "Lubricant thermo-viscosity effects on turbocharger performance at low engine load," Applied Thermal Engineering, vol. 139, pp. 334-340, 2018.

[19] P. Podevin, A. Clenci, and G. Descombes, "Influence of the lubricating oil pressure and temperature on the performance at low speeds of a centrifugal compressor for an automotive engine," Applied Thermal Engineering, vol. 31, no. 2-3, pp. 194-201, 2011.

[20] S. M. Chun, "Aeration effects on the performance of a turbocharger journal bearing," Tribology International, vol. 41, no. 4, pp. 296-306, 2008.

[21] B. Zhang, H. Zuo, Z. Huang, J. Tan, and Q. Zuo, "Endpoint forecast of different diesel-biodiesel soot filtration process in diesel particulate filters considering ash deposition," Fuel, vol. 272, Article ID 117678, 2020.

[22] F. Piscaglia and G. Ferrari, "A novel 1D approach for the simulation of unsteady reacting flows in diesel exhaust aftertreatment systems," Energy, vol. 34, no. 12, pp. 2051-2062, 2009.

[23] B. Zhang, E. Jiaqiang, J. Chen et al., "Multidisciplinary design optimization of the diesel particulate filter in the composite regeneration process," Applied Energy, vol. 181, pp. 14-28, 2016.

[24] E. Jiaqiang, X. Zhao, L Xie et al., "Performance enhancement of microwave assisted regeneration in a wall-flow diesel 
particulate filter based on field synergy theory," Energy, vol. 169, pp. 719-729, 2019.

[25] S. Das, B. Saha, and S. Bhaumik, "Experimental study of nucleate pool boiling heat transfer of water by surface functionalization with crystalline TiO 2 nanostructure," Applied Thermal Engineering, vol. 113, pp. 1345-1357, 2017.

[26] G. Wu, Z. L. Li, S. Abubakar, Y. L. Li, and Y. Q. Li, "Numerical study on effects of Key factors on performance of $\mathrm{CeO}_{2}$-based catalyzed diesel particulate filter," Journal of Thermal Science, vol. 29, pp. 1398-1409, 2019.

[27] D. Zhao, E. Gutmark, and P. de Goey, "A review of cavitybased trapped vortex, ultra-compact, high-g, inter-turbine combustors," Progress in Energy and Combustion Science, vol. 66, pp. 42-82, 2018.

[28] S. Marelli, G. Marmorato, and M. Capobianco, "Evaluation of heat transfer effects in small turbochargers by theoretical model and its experimental validation," Energy, vol. 112, pp. 264-272, 2016.

[29] F. Payri, P. Olmeda, F. J. Arnau, A. Dombrovsky, and L. Smith, "External heat losses in small turbochargers: model and experiments," Energy, vol. 71, pp. 534-546, 2014.

[30] J. Galindo, A. Tiseira, R. Navarro, D. Tarí, and C. M. Meano, "Effect of the inlet geometry on performance, surge margin and noise emission of an automotive turbocharger compressor," Applied Thermal Engineering, vol. 110, pp. 875-882, 2016.

[31] M. Sjeric', I. Taritaš, R. Tomic', M. Blažic', D. Kozarac, and Z. Lulic', "Efficiency improvement of a spark-ignition engine at full load conditions using exhaust gas recirculation and variable geometry turbocharger-numerical study," Energy Conversion and Management, vol. 125, pp. 26-39, 2016.

[32] C. O. Katsanos, D. T. Hountalas, and T. C. Zannis, "Simulation of a heavy-duty diesel engine with electrical turbocompounding system using operating charts for turbocharger components and power turbine," Energy Conversion and Management, vol. 76, pp. 712-724, 2013.

[33] A. Romagnoli and R. Martinez-Botas, "Heat transfer analysis in a turbocharger turbine: an experimental and computational evaluation," Applied Thermal Engineering, vol. 38, pp. 58-77, 2012.

[34] X. Gao, B. Savic, and R. Baar, "A numerical procedure to model heat transfer in radial turbines for automotive engines," Applied Thermal Engineering, vol. 153, pp. 678-691, 2019.

[35] L. Huang, C. Ma, Y. Li, J. Gao, and M. Qi, “Applying neural networks $(\mathrm{NN})$ to the improvement of gasoline turbocharger heat transfer modeling," Applied Thermal Engineering, vol. 141, pp. 1080-1091, 2018.

[36] J. R. Serrano, P. Olmeda, F. J. Arnau, M. A. Reyes-Belmonte, and H. Tartoussi, "A study on the internal convection in small turbochargers. Proposal of heat transfer convective coefficients," Applied Thermal Engineering, vol. 89, pp. 587-599, 2015.

[37] J. R. Serrano, A. Tiseira, L. M. García-Cuevas, and T. R. Usaquén, "Adaptation of a 1-D tool to study transient thermal in turbocharger bearing housing," Applied Thermal Engineering, vol. 134, pp. 564-575, 2018.

[38] M. Schinnerl, J. Ehrhard, M. Bogner, and J. Seume, "Correcting turbocharger performance measurements for heat transfer and friction," Journal of Engineering for Gas Turbines and Power-Transactions of the Asme, vol. 140, pp. 1-13, 2018.

[39] Z. ZhangZ. Tu et al., "Effect analysis on flow and boiling heat transfer performance of cooling water-jacket of bearing in the gasoline engine turbocharger," Applied Thermal Engineering, vol. 130, pp. 754-766, 2018.

[40] T. Van Gestel, J. A. K. Suykens, D.-E. Baestaens et al., "Financial time series prediction using least squares support vector machines within the evidence framework," IEEE Transactions on Neural Networks, vol. 12, no. 4, pp. 809-821, 2001.

[41] R. D. Burke, P. Olmeda, F. J. Arnau, and M. Reyes-Belmonte, "Modelling of turbocharger heat transfer under stationary and transient conditions," in Proceedings of the 11th International Conference on Turbochargers and Turbocharging, pp. 103-112, London, UK, 2014.

[42] J. A. K. Suykens and J. Vandewalle, "Least squares support vector machine classifiers," Neural Processing Letters, vol. 9, no. 3, pp. 293-300, 1999.

[43] J. Li, W. M. Yang, H. An, and D. Zhao, "Effects of fuel ratio and injection timing on gasoline/biodiesel fueled RCCI engine: a modeling study," Applied Energy, vol. 155, pp. 59-67, 2015.

[44] K. Wei, Y. Yang, H. Zuo, and D. Zhong, "A review on ice detection technology and ice elimination technology for wind turbine," Wind Energy, vol. 23, no. 3, pp. 433-457, 2020.

[45] H. Zuo, G. Liu, J. Zuo et al., "Catastrophic analysis on the stability of a large dish solar thermal power generation system with wind-induced vibration," Solar Energy, vol. 183, pp. 40-49, 2019.

[46] H. Chu, Y. Ya, X. Nie, and F. Qiao, "Effects of adding cyclohexane, n-hexane, ethanol, and 2,5-dimethylfuran to fuel on soot formation in laminar coflow n-heptane/iso-octane diffusion flame," Combustion and Flame, vol. 225, pp. 120135, 2021.

[47] F. Zhang, G. Liao, J. E, J. Chen, and E. Leng, "Comparative study on the thermodynamic and economic performance of novel absorption power cycles driven by the waste heat from a supercritical CO2 cycle," Energy Conversion and Management, vol. 228, Article ID 113671, 2021.

[48] Q. Peng, W. Yang, J. Xu et al., "Investigation on premixed H2/ $\mathrm{C} 3 \mathrm{H} 8 /$ air combustion in porous medium combustor for the micro thermophotovoltaic application," Applied Energy, vol. 260, p. 114352, 2020.

[49] H. Zuo, J. Tan, K. Wei, Z. Huang, D. Zhong, and F. Xie, "Effects of different poses and wind speeds on wind-induced vibration characteristics of a dish solar concentrator system," Renewable Energy, vol. 168, pp. 1308-1326, 2021.

[50] D. Han, E. Jiaqiang, Y. Deng et al., "A review of studies using hydrocarbon adsorption material for reducing hydrocarbon emissions from cold start of gasoline engine," Renewable and Sustainable Energy Reviews, vol. 135, Article ID 110079, 2021.

[51] E. Jiaqiang, M. Zhao, Q. Zuo et al., "Effects analysis on diesel soot continuous regeneration performance of a rotary microwave-assisted regeneration diesel particulate filter," Fuel, vol. 260, Article ID 116353, 2020.

[52] Q. Zuo, Y. Tang, G. Zhu et al., "Investigations on the soot combustion performance enhancement of a catalytic gasoline particulate filter in equilibrium state for reducing the BSFC of gasoline direct injection engine," Fuel, vol. 284, Article ID 119032, 2021.

[53] Y. Xie, Q. Zuo, G. Zhu et al., "Investigations on the soot combustion performance enhancement of an improved catalytic gasoline particulate filter regeneration system under different electric heating powers," Fuel, vol. 283, Article ID 119301, 2021.

[54] E. Jiaqiang, P. Zheng, D. Han, X. Zhao, and Y. Deng, "Effects analysis on soot combustion performance enhancement in a 
rotary diesel particulate filter unit during continuous microwave heating," Fuel, vol. 276, Article ID 118043, 2020.

[55] H. Chu, L. Xiang, X. Nie, Y. Ya, M. Gu, and E. Jiaqiang, "Laminar burning velocity and pollutant emissions of the gasoline components and its surrogate fuels: a review," Fuel, vol. 269, Article ID 117451, 2020.

[56] H. Chu, L. Xiang, X. Nie, Y. Ya, M. Gu, and E. Jiaqiang, "Effects of ethanol and 2, 5-dimethylfuran addition on the morphology and nanostructure evolution of soot in gasoline primary reference fuel-air coflow diffusion flames," Fuel, vol. 269, Article ID 118711, 2020.

[57] G. Wu, X. Wang, S. Abubakar, Y. Li, and Z. Liu, "A realistic skeletal mechanism for the oxidation of biodiesel surrogate composed of long carbon chain and polyunsaturated compounds," Fuel, vol. 289, Article ID 119934, 2021. 